\title{
PERBANDINGAN TRANSFORMASI LAPLACE DAN TRANSFORMASI SHEHU UNTUK MEENYELESAIKAN PERSAMAAN INTEGRAL VOLTERRA JENIS PERTAMA
}

\author{
Agus Dahlia ${ }^{1}$, Rahma Qudsi $^{2}$ \\ Pendidikan Matematika FKIP Universitas Islam Riau, J1. Kaharuddin Nasution 113 Pekanbaru Riau Indonesia ${ }^{1,2}$ \\ e-mail: agus.dahlia@edu.uir.ac.id ${ }^{1}$ \\ e-mail: $\underline{\text { rahma.qudsi@edu.uir.ac.id }}{ }^{2}$
}

\begin{abstract}
ABSTRAK
Tulisan ini merupakan studi perbandingan antara Transformasi Laplace dan transformasi integral baru Shehu untuk menyelesaikan Persamaan Integral Volterra Jenis Pertama. Untuk mengilustrasikan kedua metode yang diusulkan, tiga persamaan Volterra Integral yang berbeda dari contoh jenis pertama disajikan, yang selanjutnya hasilnya dibandingkan.
\end{abstract}

\section{Kata kunci :}

Persamaan Integral Volterra; Transformasi Laplace; Transformasi Shehu.

\section{ABSTRACT}

In this paper, a comparative study between Laplace Transform and new integral transform Shehu for solving Volterra Integral Equations of First Kind. To illustrate both of the proposed methods, three different Volterra Integral equations of first kind examples are presented. The results were compared.

Keywords :

Laplace Transform; Shehu Tranform; Volterra Itegral Equations.

\section{PENDAHULUAN}

Dalam beberapa tahun terakhir beberapa metode transformasi integral untuk menyelesaikan persamaan integral telah diperkenalkan, termasuk Transformasi Sadik (Ali \& Chaudhary, 2011), Transformasi Kamal (Kamal Sedeeg, 2016), Transformasi Shehu (Maitama \& Zhao, 2019), Transformasi Mahgoub (Mohand M. Abdelrahim Mahgoub, 2016), dan lainnya yang merupakan pengembangan dari Laplace Transformasi (Upadhyaya, 2019). Metode ini sangat berguna untuk menyelesaikan masalah matematika yang sering dijumpai pada aplikasi matematika, fisika, dan teknik. Masalah matematika yang muncul berupa persamaan diferensial parsial linier dan nonlinier yang sangat sulit untuk diselesaikan dan solusi eksak dari persamaan tersebut juga sangat sulit didapatkan. Salah satu persamaan diferensial parsial nonlinier yang sering dijumpai dalam aplikasi matematika adalah Persamaan Integral Volterra.

Beberapa penelitian telah menggunakan metode transformasi integral untuk menyelesaikan persamaan integral Volterra, termasuk Aggarwal, dkk. (Aggarwal, et al., 2019; Aggarwal et al., 2018b, 2018a, 2020; Aggarwal \& Sharma, 2019) dan Sharjeel (Sharjeel \& Barakzai, 2019). Salah satu metode transformasi integral baru untuk menyelesaikan masalah persamaan diferensial adalah Transformasi Shehu. Transformasi Shehu diperkenalkan oleh (Maitama \& Zhao, 2019) dan Aggarwal et al telah menggunakannya dalam (Aggarwal et al., 2020) untuk menyelesaikan Persamaan Integral Volterra. Makalah ini memperkenalkan studi banding untuk menyelesaikan Persamaan Integrasi Volterra jenis pertama dengan menggunakan transformasi Laplace dan transformasi Shehu. 


\section{$\pi$ (Phi)}

\section{TEORI DASAR}

Pada bagian ini, definisi yang diperlukan dan sifat dasar tentang transformasi Laplace dan transformasi Shehu, yang digunakan lebih lanjut dalam makalah ini disajikan.

\section{Transformasi Laplace}

Transformasi Laplace $\mathrm{V}=\mathrm{V}(\mathrm{s})$ dari fungsi $\mathrm{v}=\mathrm{v}(\mathrm{t})$ didefinisikan oleh (Boyce \& DiPrima, 2012)

$$
\mathcal{L}(\mathrm{f})(\mathrm{s})=\mathrm{V}(\mathrm{s})=\int_{0}^{\infty} \mathrm{e}^{-\mathrm{ts}} \mathrm{v}(\mathrm{t}) \mathrm{dt} .
$$

Diintegralkan terhadap "t".

Transformasi Laplace dari beberapa fungsi sederhana adalah sebagai berikut (Aggarwal \& Sharma, 2019):

1. jika $v(t)=1$ maka $\mathcal{L}(1)=\frac{1}{v}$

2. jika $\mathrm{v}(\mathrm{t})=\mathrm{t}$ maka $\mathcal{L}(\mathrm{t})=\left(\frac{1}{\mathrm{v}}\right)^{2}$

3. jika $v(t)=t^{2}$ maka $\mathcal{L}\left(t^{2}\right)=2$ ! $\left(\frac{1}{v}\right)^{3}$

4. jika $v(t)=t^{n}, n \in N$ maka $\mathcal{L}\left(t^{n}\right)=$ $n !\left(\frac{1}{v}\right)^{n+1}$

5. jika $v(t)=t^{n}, n>-1 \quad$ maka $\mathcal{L}\left(t^{n}\right)=\Gamma(n+1)\left(\frac{1}{v}\right)^{n+1}$

6. jika $v(t)=e^{a t}$ maka $\quad \mathcal{L}\left(e^{a t}\right)=$ $\frac{1}{v-a u}$

7. jika $v(t)=\sin a t \quad$ maka $\mathcal{L}(\sin a t)=\frac{a}{\left(v^{2}+a^{2}\right)}$

8. jika $v(t)=\cos a t \quad$ maka $\mathcal{L}(\cos a t)=\frac{v}{\left(v^{2}+a^{2}\right)}$

Sifat-sifat dasar transformasi Laplace:

1. Sifat Linieritas (Aggarwal \& Sharma, 2019),

$$
\begin{aligned}
& \mathcal{L}[\operatorname{av}(\mathrm{t})+\mathrm{bw}(\mathrm{t})] \\
& \quad=\mathrm{a} \mathcal{L}[\mathrm{v}(\mathrm{t})]+\mathrm{b} \mathcal{L}[\mathrm{w}(\mathrm{t})]
\end{aligned}
$$

dengan $\mathrm{a}, \mathrm{b}$ adalah konstanta sembarang.

2. Sifat perubahan skala (Aggarwal et al., 2019)
Jika fungsi $\mathrm{v}(\mathrm{t})$ terdapat dalam himpunan $\mathrm{A}$, maka

$$
\mathcal{L}[\mathrm{v}(\mathrm{t})]=\frac{1}{\mathrm{a}} \mathrm{v}\left(\frac{\mathrm{s}}{\mathrm{a}}\right) .
$$

3. Sifat turunan (Aggarwal et al., 2019)

$$
\text { Jika } \mathcal{L}\left[\mathrm{F}^{\prime}(\mathrm{t})\right]=\mathrm{f}(\mathrm{s}) \text {, maka }
$$

$$
\mathcal{L}\left[\mathrm{F}^{\prime}(\mathrm{t})\right]=\mathrm{sf}(\mathrm{s})-\mathrm{F}(0)
$$

$$
\begin{gathered}
\mathcal{L}\left[\mathrm{F}^{\prime \prime}(\mathrm{t})\right]=\mathrm{s}^{2} \mathrm{f}(\mathrm{s})-\mathrm{F}(0)-\mathrm{F}^{\prime}(0) \\
\begin{aligned}
\mathcal{L}\left[\mathrm{F}^{(\mathrm{n})}(\mathrm{t})\right] & =\mathrm{s}^{\mathrm{n}} \mathrm{f}(\mathrm{s})-\mathrm{s}^{\mathrm{n}-1} \mathrm{~F}(0) \\
& -\mathrm{s}^{\mathrm{n}-2} \mathrm{~F}^{\prime}(0)-\cdots \\
- & \mathrm{F}^{(\mathrm{n}-1)}(0)
\end{aligned}
\end{gathered}
$$

4. Sivat konvolusi (Aggarwal et al., 2019)

$$
\begin{aligned}
\mathrm{F}(\mathrm{t}) * \mathrm{G}(\mathrm{t})= & \mathrm{F} * \mathrm{G}=\int_{0}^{\mathrm{t}} \mathrm{F}(\mathrm{x}) \mathrm{G}(\mathrm{t}-\mathrm{x}) \mathrm{dx} \\
& =\int_{0}^{\mathrm{t}} \mathrm{F}(\mathrm{t}-\mathrm{x}) \mathrm{G}(\mathrm{x}) \mathrm{dx}
\end{aligned}
$$

\section{Transformasi Shehu}

Definisi 1.(Maitama \& Zhao, 2019) Transformasi Shehu dari fungsi $v(t)$ dari barisan eksponen didefinisikan sebagai himpunan fungsi,

$$
\begin{aligned}
A=\{v(t): \exists N & , \eta_{1}, \eta_{2}>0,|v(t)| \\
& <N \exp \left(\frac{|t|}{\eta_{i}}\right), \text { if } t \\
& \left.\in(-1)^{i} \times[0, \infty)\right\},
\end{aligned}
$$

dengan integral berikut

$$
\begin{gathered}
S[v(t)]=V(s, u)=\int_{0}^{\infty} \exp \left(\frac{-s t}{u}\right) v(t) d t \\
=\lim _{\alpha \rightarrow \infty} \int_{0}^{\alpha} \exp \left(\frac{-s t}{u}\right) v(t) d t ; s>0, u \\
>0 .
\end{gathered}
$$

dengan $S$ disebut sebagai operator transformasi Shehu. Operator ini dikatakan konvergen jika limit dari integral ada dan dikatakan divergen jika sebaliknya. 
$\pi$ (Phi)

Transformasi Shehu dikatakan ada jika syarat perlu berikut ini dipenuhi (Maitama \& Zhao, 2019).

1. $\mathrm{v}(\mathrm{t})$ adalah kontinu sepotong-sepotong di setiap interval berhingga $0 \leq \mathrm{t} \leq \beta$; dan

2. Barisan eksponen $a$ untuk $\mathrm{t}>\beta$.

Transformasi Shehu dari beberapa fungsi sederhana(Aggarwal, et al., 2019):

1. Jika $v(t)=1$ maka $S(1)=\frac{u}{v}$

2. Jika $v(t)=t$ maka $S(t)=\left(\frac{u}{v}\right)^{2}$

3. Jika $v(t)=t^{2}$ maka $S\left(t^{2}\right)=2$ ! $\left(\frac{u}{v}\right)^{3}$

4. Jika $\mathrm{v}(\mathrm{t})=\mathrm{t}^{\mathrm{n}}, \mathrm{n} \in \mathrm{N}$ maka $\mathrm{S}\left(\mathrm{t}^{\mathrm{n}}\right)=$ $n !\left(\frac{u}{v}\right)^{n+1}$

5. Jika $\mathrm{v}(\mathrm{t})=\mathrm{t}^{\mathrm{n}}, \mathrm{n}>-1$ maka $\mathrm{S}\left(\mathrm{t}^{\mathrm{n}}\right)=$ $\Gamma(\mathrm{n}+1)\left(\frac{\mathrm{u}}{\mathrm{v}}\right)^{\mathrm{n}+1}$

6. Jika $\mathrm{v}(\mathrm{t})=\mathrm{e}^{\mathrm{at}} \operatorname{maka} \mathrm{S}\left(\mathrm{e}^{\mathrm{at}}\right)=\frac{\mathrm{u}}{\mathrm{v}-\mathrm{au}}$

7. Jika $\mathrm{v}(\mathrm{t})=\sin$ at maka $\mathrm{S}(\sin \mathrm{at})=$ $\frac{a u^{2}}{\left(v^{2}+a^{2} u^{2}\right)}$

8. Jika $\mathrm{v}(\mathrm{t})=\mathrm{cos}$ at maka $\mathrm{S}(\cos \mathrm{at})=$ $\frac{u v}{\left(v^{2}+a^{2} u^{2}\right)}$

Sifat-sifat dasar Transformasi Shehu (Maitama \& Zhao, 2019):

1. Sifat linieritas.

Jika fungsi $\alpha v(t)$ dan $\beta w(t)$ terdapat dalam himpunan $A$, maka $(\alpha v(t)+$ $\beta \mathrm{w}(\mathrm{t})) \in \mathrm{A}$, dengan $\alpha$ dan $\beta$ sembarang konstanta bukan nol, dan

$$
\begin{aligned}
& \mathrm{S}[\alpha \mathrm{v}(\mathrm{t})+\beta \mathrm{w}(\mathrm{t})] \\
& =\alpha \mathrm{S}[\mathrm{v}(\mathrm{t})]+\beta \mathrm{S}[\mathrm{w}(\mathrm{t})] .
\end{aligned}
$$

2. Sifat perubahan skala.

Jika fungsi $\mathrm{v}(\beta \mathrm{t})$ terdapat dalam himpunan $A$, dengan $\beta$ adalah konstanta sembarang, maka

$$
\mathrm{S}[\mathrm{v}(\beta \mathrm{t})]=\frac{\mathrm{u}}{\beta} \mathrm{V}\left(\frac{\mathrm{s}}{\beta}, \mathrm{u}\right) .
$$

3. Sifat turunan.

Jika $\mathrm{v}^{(\mathrm{n})}(\mathrm{t})$ adalah turunan ke-ndari fungsi $\mathrm{v}(\mathrm{t}) \in \mathrm{A}$ terhadap ' $\mathrm{t}$ ', maka Transformasi Shehu didefinisikan sebagai

$$
\begin{aligned}
& =\frac{s^{n}}{u^{n}} V(s, u) \\
& -\sum_{k=0}^{n-1}\left(\frac{s}{u}\right)^{n-(k+1)} v^{(k)}(0)
\end{aligned}
$$

3. Sifat Konvolusi (Aggarwal, et al., 2019)

$$
\mathrm{S}\left[\mathrm{v}_{1}(\mathrm{t}) * \mathrm{v}_{2}(\mathrm{t})\right]=\mathrm{S}\left[\mathrm{v}_{1}(\mathrm{t})\right] \mathrm{S}\left[\mathrm{v}_{2}(\mathrm{t})\right]
$$

dengan $\mathrm{v}_{1}(\mathrm{t}) * \mathrm{v}_{2}(\mathrm{t})$ didefinisikan oleh

$$
\begin{aligned}
\mathrm{v}_{1}(\mathrm{t}) * \mathrm{v}_{2}(\mathrm{t}) & =\int_{0}^{\mathrm{t}} \mathrm{v}_{1}(\mathrm{t}-\mathrm{x}) \mathrm{v}_{2}(\mathrm{x}) \mathrm{dx} \\
& =\int_{0}^{\mathrm{t}} \mathrm{v}_{1}(\mathrm{x}) \mathrm{v}_{2}(\mathrm{t}-\mathrm{x}) d \mathrm{x}
\end{aligned}
$$

\section{HASIL DAN PEMBAHASAN}

\section{Persamaa Integral Volterra Jenis Satu}

Persamaan Volterra jenis pertama diberikan oleh [6]-[9], [14]

$$
f(x)=\int_{0}^{x} K(x, t) u(t) d t .
$$

dengan fungsi yang tidak diketahui $u(x)$ dalam integral agan ditentukan. Kernel fungsi-fungsi yang diberikan adalah fungsi bernilai Riil.

Misalkan kernel $K(x, t)$ dari persamaan (7) adalah tipe kernel konvolusionalyang selisihnya dapat dinyatakan. Sehingga, persamaan (1) dapat dinyatakan sebagai:

$$
f(x)=\int_{0}^{x} K(x-t) u(t) d t .
$$

\section{Aplikasi}

Pada bagian ini, Transformasi Laplace dan Transformasi Shehu diaplikasikan pada tiga contoh dari persamaan-persamaan integral Volterra jenis pertama dan kemudian hasil yang diperoleh dari keduanya dibandingkan.

Contoh 1: Misalkan persamaan integral Volterra jenis pertama 


$$
x=\int_{0}^{x} e^{(x-t)} u(t) d t
$$

Solusi dengan menggunakan Transform Laplace

Lakukan transformasi Laplace pada kedua sisi persamaan (9), sehingga diperoleh

$$
\begin{aligned}
\mathcal{L}[x] & =\mathcal{L}\left[\int_{0}^{x} e^{(x-t)} u(t) d t\right] \\
\frac{1}{v^{2}} & =\mathcal{L}\left[e^{x}\right] \mathcal{L}[u(x)] \\
\frac{1}{v^{2}} & =\left[\frac{1}{v-1}\right] \mathcal{L}[u(x)] \\
\mathcal{L}[u(x)] & =\frac{v-1}{v^{2}}
\end{aligned}
$$

Lakukan invers transformasi Laplace transform dari kedua sisi persamaan (11), solusi eksak yang diperoleh

$$
\begin{aligned}
& u(x)=\mathcal{L}^{-1}\left[\frac{v-1}{v^{2}}\right] \\
& u(x)=\mathcal{L}^{-1}\left[\frac{1}{v}\right]-\mathcal{L}^{-1}\left[\frac{1}{v^{2}}\right] \\
& u(x)=1-x
\end{aligned}
$$

\section{Solusi dengan menggunakan transformasi}

\section{Shehu}

Lakukan transformasi Shehu pada kedua sisi persamaan (9), sehingga diperoleh

$$
S[x]=S\left[\int_{0}^{x} e^{(x-t)} u(t) d t\right]
$$

$\frac{u^{2}}{v^{2}}=S\left[e^{x}\right] S[u(x)]$

$\frac{u^{2}}{v^{2}}=\left[\frac{u}{v-u}\right] S[u(x)]$

$S[u(x)]=\frac{u}{v}-\left(\frac{u}{v}\right)^{2}$

Lakukan invers transformasi Shehu transform dari kedua sisi persamaan (14), solusi eksak yang diperoleh

$u(x)=S^{-1}\left[\frac{u}{v}-\left(\frac{u}{v}\right)^{2}\right]$
$u(x)=S^{-1}\left[\frac{u}{v}\right]-S^{-1}\left[\left(\frac{u}{v}\right)^{2}\right]$

$u(x)=1-x$

Contoh 2: Misalkan persamaan integral Volterra jenis pertama

$$
1+x-e^{x}=\int_{0}^{x}(t-x) u(t) d t
$$

Sebelum menyelesaikan persamaan ini, ingat bahwa $(t-x)=-(x-t)$.

Solusi dengan menggunakan Transform Laplace

Lakukan transformasi Laplace pada kedua sisi persamaan (16), sehingga diperoleh

$$
\mathcal{L}\left[1+x-e^{x}\right]=\mathcal{L}\left[\int_{0}^{x}(t-x) u(t) d t\right]
$$

$\frac{1}{v}+\frac{1}{v^{2}}-\frac{1}{v-1}=-\mathcal{L}[(x)] \mathcal{L}[u(x)]$

$\frac{1}{v}+\frac{1}{v^{2}}-\frac{1}{v-1}=-\frac{1}{v^{2}} \mathcal{L}[u(x)]$

$\mathcal{L}[u(x)]=\frac{1}{v-1}$

Lakukan invers transformasi Laplace transform dari kedua sisi persamaan (18), solusi eksak yang diperoleh

$u(x)=\mathcal{L}^{-1}\left[\frac{1}{v-1}\right]$

$u(x)=e^{x}$

Solusi dengan menggunakan transformasi Shehu

Lakukan transformasi Shehu pada kedua sisi persamaan (16), sehingga diperoleh

$$
\begin{aligned}
& S\left[1+x-e^{x}\right]=S\left[\int_{0}^{x}(t-x) u(t) d t\right] \\
& \frac{u}{v}+\frac{u^{2}}{v^{2}}-\frac{u}{v-u}=-S[(x)] S[u(x)] \\
& \frac{u}{v}+\frac{u^{2}}{v^{2}}-\frac{u}{v-u}=-\frac{u^{2}}{v^{2}} S[u(x)] \\
& \mathcal{L}[u(x)]=\frac{u}{v-u}
\end{aligned}
$$


Lakukan invers transformasi Shehu transform dari kedua sisi persamaan (21),

$$
\frac{u}{v-u}-\frac{u^{2}}{v^{2}+u^{2}}-\frac{u v}{v^{2}+u^{2}}
$$$$
\text { solusi eksak yang diperoleh }
$$$$
u(x)=S^{-1}\left[\frac{u}{v-u}\right]
$$$$
u(x)=e^{x}
$$

Contoh 2: Misalkan persamaan integral

Volterra jenis pertama

$$
e^{x}-\sin x-\cos x=\int_{0}^{x} 2 e^{x-t} u(t) d t
$$

Solusi dengan menggunakan Transform Laplace

Lakukan transformasi Laplace pada kedua sisi persamaan (23), sehingga diperoleh

$$
\begin{gathered}
\mathcal{L}\left[e^{x}-\sin x-\cos x\right] \\
=\mathcal{L}\left[\int_{0}^{x} 2 e^{x-t} u(t) d t\right] \\
\frac{1}{v-1}-\frac{1}{v^{2}+1}-\frac{v}{v^{2}+1} \\
=2 \mathcal{L}\left[\left(e^{x}\right)\right] \mathcal{L}[u(x)] \\
\frac{1}{v-1}-\frac{1}{v^{2}+1}-\frac{v}{v^{2}+1} \\
=2 \frac{1}{v-1} \mathcal{L}[u(x)] \\
\mathcal{L}[u(x)]=\frac{1}{v^{2}+1}
\end{gathered}
$$

Lakukan invers transformasi Laplace transform dari kedua sisi persamaan (25), solusi eksak yang diperoleh

$u(x)=\mathcal{L}^{-1}\left[\frac{1}{v^{2}+1}\right]$

$u(x)=\sin x$

Solusi dengan menggunakan transformasi

\section{Shehu}

Lakukan transformasi Shehu pada kedua sisi persamaan (23), sehingga diperoleh

$$
\begin{aligned}
S\left[e^{x}-\sin x-\right. & \cos x] \\
& =S\left[\int_{0}^{x} 2 e^{x-t} u(t) d t\right]
\end{aligned}
$$

Agus Dahlia, Rahma Qudsi

Perbandingan Transformasi Laplace Dan Transformasi Shehu Untuk Meenyelesaikan Persamaan Integral Volterra Jenis Pertama

Lakukan invers transformasi Shehu transform dari kedua sisi persamaan (28), solusi eksak yang diperoleh

$$
\begin{aligned}
& u(x)=\mathcal{L}^{-1}\left[\frac{u^{2}}{v^{2}+u^{2}}\right] \\
& u(x)=\sin x
\end{aligned}
$$

\section{SIMPULAN DAN SARAN}

Dalam tulisan ini, transformasi Laplace dan transformasi Shehu telah daplikasikan untuk menyelesaikan persamaan integral Volterra. Dari contoh yang diberikan pada bagian 3, dapat dilihat bahwa hasil yang diperoleh dari kedua integral transformasi ini adalah sama. Jadi, dapat disimpulkan bahwa transformasi Shehu adalah alat alternatif untuk menyelesaikan persamaan integral Volterra jenis pertama.

\section{DAFTAR PUSTAKA}

Aggarwal, S., Gupta, A. R., \& Sharma, S. D. (2019). A New Application of Shehu Transform for Handling Volterra Integral Equations of First Kind. International Journal of Research in Advent Technology, 7(4), 438-445. https://doi.org/10.32622/ijrat.74201915 1

Aggarwal, S., \& Sharma, N. (2019). Laplace Transform for the Solution of First Kind Linear Volterra Integral Equation. J Adv Res Appl Math Stat, 4(3\&4), 16 23.

Aggarwal, S., Sharma, N., \& Chauhan, R. (2018a). Application of Elzaki 
$\pi$ (Phi)

Transform for Solving Linear Volterra Integral Equations of First Kind. International Journal of Research in Advent Technology, 6, 3687-3692. www.ijrat.org

Aggarwal, S., Sharma, N., \& Chauhan, R. (2018b). Application of Kamal Transform for Solving Linear Volterra Integral Equations of First Kind. International Journal of Research in Advent Technology, 6(8). www.ijrat.org Aggarwal, S., Singh, A., Kumar, A., \& Kumar, N. (2019). Application of Laplace Transform for Solving Improper Integrals whose Integrand Consisting Error Function. Journal of Advanced Research in Applied Mathematics and Statistics, 4(2), 1-7.

Aggarwal, S., Vyas, A., \& Sharma, S. D. (2020). Analytical Solution of First Kind Volterra Integro- Differential Equation Using Sadik Transform. International Journal of Research and Innovation in Applied Science (IJRIAS) I, V(VIII), 73-80.

Ali, S. S., \& Chaudhary, M. S. (2011). On a new integral transform and solution of some integral equations. International Journal of Pure and Applied Mathematics, 73(3), 299-308.

Boyce, W. E., \& DiPrima, R. C. (2012). Elementary Differential Equations and Boundary Value Problems. In D. Dietz \& J. Sinacori (Eds.), John Wiley \& Sons, Inc (10th ed.). John Wiley \& Sons, Inc.

Kamal Sedeeg, A. H. (2016). The New Integral "Kransform "Kamal Transform." Advances in Theoretical and Applied Mathematics, 11(4), 451458. http://www.ripublication.com

Maitama, S., \& Zhao, W. (2019). New integral transform: Shehu transform a generalization of Sumudu and lapalace transform for solving differential equations. ArXiv, 1947, 1-22. https://doi.org/10.28924/2291-8639-172019-167

Mohand M. Abdelrahim Mahgoub. (2016). The new integral transform "Mahgoub transform." Global Journal of Pure and Applied Mathematics, 11, 391-398.

Sharjeel, S., \& Barakzai, M. A. K. (2019). Some New Applications of Elzaki Transform for Solution of Linear Volterra Type Integral Equations. Journal of Applied Mathematics and Physics, $\quad$ 07(08), 1877-1892. https://doi.org/10.4236/jamp.2019.7812 9

Upadhyaya, L. M. (2019). Introducing the upadhyaya integral transform. Bulletin of Pure \& Applied SciencesMathematics and Statistics, 38e(1), 471. https://doi.org/10.5958/23203226.2019 .00051 .1 